Review

\title{
Priming the Surface of Orthopedic Implants for Osteoblast Attachment in Bone Tissue Engineering
}

\author{
Kiat Hwa Chan², Shuangmu Zhuo ${ }^{1 凶}$, Ming $\mathrm{Ni}^{3^{\bowtie}}$ \\ 1. Institute of Laser and Optoelectronics Technology, Fujian Normal University, Fuzhou 350007, China \\ 2. Institute of Bioengineering and Nanotechnology, Nanos, Singapore 138669, Singapore \\ 3. Institute of Bioengineering and Nanotechnology, Nanos, Singapore 138669, Singapore
}

\begin{abstract}
$\bowtie$ Corresponding authors: shuangmuzhuo@gmail.com or mingni.sg@gmail.com
(c) 2015 Ivyspring International Publisher. Reproduction is permitted for personal, noncommercial use, provided that the article is in whole, unmodified, and properly cited. See http://ivyspring.com/terms for terms and conditions.
\end{abstract}

Received: 2015.05.10; Accepted: 2015.07.14; Published: 2015.08.14

\begin{abstract}
The development of better orthopedic implants is incessant. While current implants can function reliably in the human body for a long period of time, there are still a significant number of cases for which the implants can fail prematurely due to poor osseointegration of the implant with native bone. Increasingly, it is recognized that it is extremely important to facilitate the attachment of osteoblasts on the implant so that a proper foundation of extracellular matrix (ECM) can be laid down for the growth of new bone tissue. In order to facilitate the osseointegration of the implant, both the physical nanotopography and chemical functionalization of the implant surface have to be optimized. In this short review, however, we explore how simple chemistry procedures can be used to functionalize the surfaces of three major classes of orthopedic implants, i.e. ceramics, metals, and polymers, so that the attachment of osteoblasts on implants can be facilitated in order to promote implant osseointegration.
\end{abstract}

Key words: orthopedic implant, osseointegration

\section{Introduction}

The utility of stem cells to regenerate whole tissues is a cherished goal in tissue engineering. As embryonic stem cells (ESCs) are capable of differentiating into osteoblasts (bone forming cells) and are relatively immune-privileged. (1) ESCs represent the ideal source of new osteoblasts for bone tissue engineering. However, the clinical utility of ESCs is currently still limited because of 1) the ethical and safety issues associated with their use and 2) mounting evidences indicate that ESCs can generate teratomas upon transplantation into the patient.(2) Therefore, researchers are focused on utilizing other types of stem cells, especially bone marrow stromal cells (BMSCs).(3) BMSC is a type of non-hematopoietic stem cell that was found in bone marrow by Friedenstein et al. in the 1960s.(4) Since then, BMSCs has shown potential in the treatment of many diseases, e.g. myocardial infarction,(5) graft-versus-host diseases,(6) diabetes,(7) gliomas,(8) and liver cirrhosis.(9)
Bone-related diseases, such as osteoarthritis and spinal cord injury, have also been treated with BMSCs. $(10,11)$ BMSCs can be isolated from the bone marrow via aspiration and purified by flow cytometry according to the definition of the International Society of Cell Therapy: BMSCs should test positive for the expression of CD73, CD90 and CD105, but negative for the expression of CD11b, CD14, CD19, CD34, CD45, CD79a and HLA-DR.(12) The expression of cell surface antigens such as STRO-1 can also be used as additional biomarkers of BMSCs.(13)

A very large number of BMSCs (nine million cells $/ \mathrm{kg}$ body weight) is required for clinical applications,(14) but the yield of BMSCs from traditional bone marrow aspiration ( 1 ppm) is very low.(15) Therefore, the expeditious ex vivo production of BMSCs is urgently needed. Current cell expansion approaches include the utility of cell factory,(16) spinner flasks,(17) rotary wall vessels,(18) hollow fi- 
ber bioreactors (19) and packed bed perfusion bioreactors.(20) In order to harvest clinical grade BMSCs, the culture media used for the ex vivo expansion of BMSCs are gradually being switched from the usual fetal bovine serum (FBS) or fetal calf serum (FCS) containing media to human platelet-derived media or totally 'xeno-free' media.(16, 17, 21, 22) This is necessary because FBS or FCS contains animal proteins that may trigger an immune response from the patient upon BMSC infusion. However, the long-term culturing of BMSCs to increase production has an inherent drawback: the BMSCs may undergo senescence, i.e. the shortening of their telomeres. $(21,23)$ This can lead to the loss of their self-renewal potential, thus limiting their usefulness in tissue engineering. To circumvent this problem, several strategies have been employed, including 1) the addition of growth factors to the culture media, 2) culturing the BMSCs under low oxygen tension or in a three-dimensional (3D) scaffold, and 3) overexpression of the human telomerase reverse transcriptase gene in BMSCs. $(21,23)$

In order to induce osteogenesis of BMSCs, a strict protocol has to be followed.(23, 24) The necessary osteogenic differentiation medium is a complex solution containing dexamethasone, ascorbic acid, and $\beta$-glycerophosphate.(24) Numerous growth factors and hormones, such as calcitriol (also known as 1,25-dihydroxyvitamin D3), bone morphogenetic proteins (BMPs),(25) or transforming growth factor- $\beta$ family members, are also required to enhance the efficiency of differentiation.(23) But besides the medium components, the biomaterial on which the BMSCs are cultured matters as well. It is important to provide an environment that resembles native bone scaffold as closely as possible so that the BMSCs can be more strongly induced to differentiate into osteoblasts.(26) Thus, 3D cell cultures are preferred over two-dimensional (2D) cell cultures as the former can mimic the spatial distribution of native bone tissue.(27) Consequently, many biomaterials have been explored as 3D scaffolds for culturing stem cells,(28) some of which (natural and synthetic peptide-based biomaterials) have also been reviewed by us.(29) However, the differentiation of stem cells is highly sensitive to the microenvironment and may not be easily maintained for an extended duration.(30) For instance, even the stiffness of the biomaterials, which can change during the course of culturing the stem cells, exerts a large impact on determining the differentiation outcome of the seeded stem cells.(31) Therefore, since the bulk mass condition for the spatiotemporal support of stem cell differentiation and growth into bone is challenging, it might be more instructive to provide a physically and chemically well-defined surface that is conducive to osteoinduc- tion of BMSCs, subsequent osteoconduction of osteoblasts, and consequent osseointegration of the implant.(32)

\section{Importance of Surface Properties in Stem Cell Attachment}

The nanotopography of stem cell culture substrates has recently been recognized to play a major role in determining the differentiation outcome of stem cells,(33) a complex process in which nanotopography exerts its influence on stem cells by affecting the focal adhesion forces the stem cells sense on the substrate surface.(34) Perhaps unsurprisingly, the nanotopography of hydroxyapatite ceramics(35) and titanium(36) have been found to greatly influence osteoinduction of BMSCs and mesenchymal stem cells (MSCs). However, in addition to the nanopatterns on the substrates, the molecules attached to the surface of the nanopatterned surface also affect stem cell differentiation. This is clearly borne out by the weak influence that even a well-defined nanopatterned surface of poly(methylmethacrylate) (PMMA) has on the osteoinduction of MSCs.(37) On the other hand, synergistic effect on osteoinduction have been observed when BMP, which can accelerate osteogenic differentiation, $(38,39)$ were immobilized on poly(glycidyl methacrylate) (PGMA).(40) Hence, it is clear that chemical functionalization of implant surface should be combined with well-defined nanopatterned implant surface to achieve maximal promotion of osteoinduction (Figure 1).

As Benoit et al. have shown, functional groups ranging from amine, phosphate, fluorobutyl to carboxylic acid on poly(ethylene glycol) (PEG) hydrogels direct human mesenchymal stem cells (hMSCs) into divergent differentiation fates.(41) Not surprisingly, and as observed before,(42) the phosphate-functionalized PEG influences hMSCs down the osteogenic pathway. Such an influence of chemical functional groups on stem cell differentiation is also observed with the surface of glass; in this case, amineor thiol-functionalized glass surface is able to promote osteogenesis of bone marrow-derived MSCs. (43) In these two examples, due to the presence of primary chemical groups (methacrylate and hydroxyl on PEG and glass surface respectively), they are relatively easy to functionalize with secondary chemical groups. However, there are many materials used to assist bone repair that are not readily functionalized, e.g. ceramics, metals and polymers. The following sections illustrate how these three types of materials can be functionalized via simple chemistry procedures in order to facilitate attachment of stem cells to promote bone growth. 


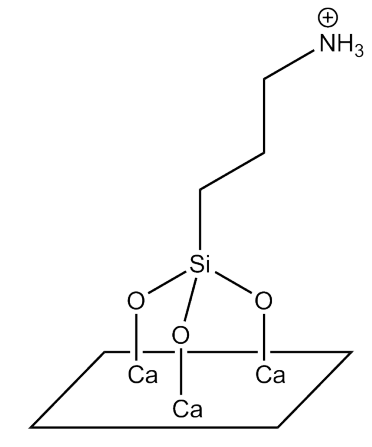

CaP ceramic surface

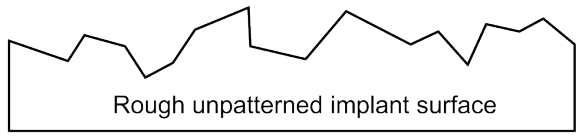

Physical nanografting of orthopedic implant surface



Chemical functionalization of orthopedic implant surface

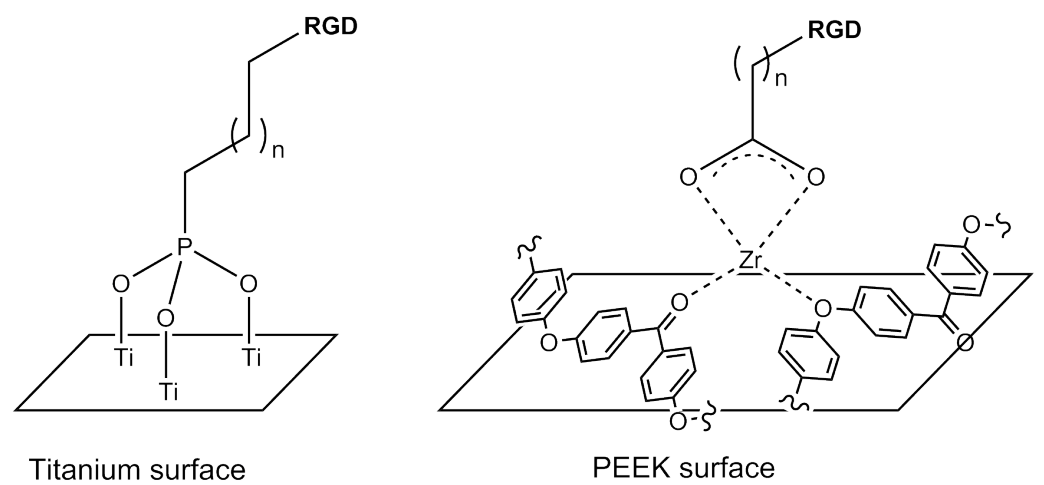

Titanium surface

PEEK surface

End result: Chemically and physically well-defined orthopedic implant surface to promote osteoinduction

Figure 1. Illustration of how physical and chemical modifications can together create an osteoinductive implant surface for osseointegration.

\subsection{Surface Functionalization of Ceramics}

Bone is a complex composite material made up of, among many others, an organic component of collagen and an inorganic component of carbonated apatite. (44) Thus, it is natural that one would seek to replace bone with, beside bone autografts or allografts, a replacement implant crafted out of carbonated apatite. This could increase the chances that the implant would be osseointegrated within the body with minimal or negligible autoimmune response to it. In this regard, calcium phosphate $(\mathrm{CaP})$ ceramics (e.g. hydroxyapatite, tricalcium phosphate ceramics) are ideal and have been widely developed as bone replacement materials.(45) However, not all $\mathrm{CaP}$ ceramics are equally effective as bone replacement materials. Upon exposure to physiological fluid, the implant surface is subject to a remodeling process involving 1) dissolution of the implant surface, 2) precipitation of new $\mathrm{CaP}$ crystals, and 3) ion exchange of the surface with the physiological fluid.(46) This is an important process that determines whether the surface characteristics of the implant would become suitable for osteoinduction, $(47,48)$ and the resultant surface bioactivity varies for different $\mathrm{CaP}$ ceramics. That the BMSCs are able to attach and grow on the implant is an important first step in the osseointegration process.(49) The first osteoblasts would secrete the extracellular matrix on the implant, which forms the foundation upon which the new bone tissue can grow. Thus, it is pertinent that the surface of the implant is processed to encourage osteoinduction and osteoconduction.(50)

Two approaches have been adopted to facilitate the attachment of osteoconductive molecules. The first approach, a physical adsorption method, makes use of the electrostatic attraction between charged molecules with either the positively charged calcium or the negatively charged phosphate on the ceramic surface. For instance, treatment of a hydroxyapatite surface with arginine led to a positively charged surface that can attract negatively charged proteins such as bovine serum albumin; conversely, treatment with aspartic acid led to a negatively charged surface that can attract positively charged proteins such as lysozyme. $(51,52)$ This approach, however, is functionally limited as the osteoconductive molecules may interact preferentially with the surface rather than with the stem cells. The second approach, a chemical bonding method, in which the hydroxyapatite surface is treated with (3-aminopropyl)triethoxysilane (APTES), 
leads to a hydroxyapatite layer functionalized with an amine group. This amine group can subsequently be used to attach various molecules, such as the cell adhesive motif Arg-Gly-Asp (RGD). (53) Even proteins, such as BMP,(54) can be attached via this chemical bonding method to improve osteoblast adhesion. Naturally, functionalizing hydroxyapatite with RGD improved the adhesion of osteoblasts onto the hydroxyapatite surface.(55) In addition, besides permitting facile functionalization with various molecules, the chemical bonding of molecules on the substrate surface is more efficient and stable compared to the physical adsorption method. $(56,57)$

\subsection{Surface Functionalization of Metals}

Despite the biocompatibility of ceramics with bone, the brittleness of ceramics is a major drawback. In this regard, metals hold a significant advantage. Titanium is one of several metals (iron, cobalt, chromium etc.) that are used in alloys for the fabrication of orthopedic implants because it possesses many desirable properties - high load-bearing capacity, compatible elastic modulus to native bone,(58) high corrosion resistance,(59) and good biocompatibility.(60) However, in a small number of recipients of titanium implants, allergic reactions in response to the implants were observed.(61, 62) In order to minimize such allergic reactions, it is necessary to osseointegrate the implant with the native bone, viz. the new bone tissue should be able to grow naturally on an osteoconductive titanium implant surface. The surface of titanium is normally coated with a tight layer of inert titanium dioxide that protects the underlying titanium from further oxidation. Such an interface does not interact chemically or biologically with cells. Thus, there is a need for an efficient method to activate the titanium surface toward stem cell attachment.

One way the titanium surface can be activated is to treat it with an organophosphonic acid, thus coating the surface with a layer of organophosphonate. As such a layer of organophosphonate is not tightly attached to the surface, it would not be stable in vivo. However, heating at $180^{\circ} \mathrm{C}$ can activate the titanium surface toward chemical reaction with the organophosphonic acid, forming a tightly bound layer of organophosphonate that is resistant to solvent wash and physical peeling by scotch tape.(63) The attachment of the organophosphonic acid to the titanium surface can be further enhanced by prior treatment of titanium with phosphoric acid, which produces a titanium(III) phosphate interface.(64) This phosphoric acid-treatment step primes the titanium surface toward stronger attachment of the organophosphonic acid. Via the "tethering by aggregation and growth" method procedure, the titanium surface is first im- mersed in a solution of the organophosphonic acid, after which the solvent is slowly evaporated to deposit a film of tightly attached organophosphonate on the titanium surface. (65)

With the establishment of a facile method to attach an organophosphonic acid onto the titanium surface, it becomes relatively easy to functionalize the titanium surface with RGD. On treatment of the titanium surface with RGD-tethered phosphonic acid, a layer of RGD could be introduced onto the titanium surface, which is stable for at least three days. (66-68) This layer of RGD increased more than 10 times the attachment of human osteoblasts to titanium compared to untreated titanium surface. The osteoblasts appeared normal with well-developed actin cytoskeleton, indicating it is possible for cells to attach on the RGD-layered titanium surface and proliferate normally. While this approach could be utilized to attach any biomolecule of interest on the titanium surface, it is limited by the accessibility to suitably functionalized phosphonic acids. This limitation can be overcome utilizing zirconium as a linking intermediary for carboxylic acids, which are much more accessible than phosphonic acids. In addition, surface patterning of titanium with cells also becomes possible.(69) Such a zirconium intermediary layer is stable under physiological conditions for up to five days and is verified to be capable of promoting bone growth in vivo.(70)

\subsection{Surface Functionalization of Polymers}

Polymers have also been extensively explored as replacement materials for bone. Some of the reasons include the low cost of polymers, the ease of tunability of polymer stress modulus, as well as the biocompatibility of polymers.(71) The use of polymers in orthopedic applications has a long history, with many examples of success. Prominent examples include the fabrication of fracture fixation devices for immobilization of fractured or broken bones, as well as Brantigan spine fusion cage for the stabilization of spine afflicted with degenerative disc disease.(72) Thus, it is natural that polymers are also being considered as replacement materials for total hip and knee replacement. However, there has only been limited success on this front, and the finger of blame can be pointed at the inability of the tissue surrounding the implant to interface properly with the polymeric implant.(72)

As with metals, the key to adapting hard polymers for orthopedic applications is to activate the surface so that a layer of cell-adhesive RGD can be attached, and zirconium tetra(tert-butoxide) has proven useful in this regard. Zirconium tetra(tert-butoxide) can react with relatively unreactive functional groups such as amide, carbamate, imide, 
and even ketone/ether linkages of nylon 6/6,(73) polyurethanes,(74) polyterephthlates,(75) and poly(aryl-ether-ether-ketone) (PEEK)(76) respectively, permitting the facile surface activation of these hard polymers. Via this method, about $40 \%$ of the nylon 6/6 surface can be functionalized with RGD,(73) a drastic improvement from previously reported values. Such an RGD-functionalized nylon $6 / 6$ is stable to aqueous hydrolysis at $\mathrm{pH} 7.5$ (up to 7 days) and facilitates the surface adhesion and spreading of NIH3T3 cells. The polyurethane surface of tecoflex®, an important material in the fabrication of synthetic vascular grafts to bypass atherosclerotic blood vessels, can be similarly functionalized to achieve up to $25 \%$ surface coverage by RGD and consequent cell attachment.(74) Such surface functionalization can thus reduce the incidence of biofouling on tecoflex ${ }^{\circledR}$ and render the vascular graft much less thrombogenic. And as with nylon 6/6 and polyurethanes, the surface of polyterephthlates can be activated and coated with a zirconium intermediary layer, which can be treated with copper sulfate and chemically reduced to metallic copper.(75) So tightly bound the metallic copper is on the polyterephthlate that the plastic material can be vigorously flexed without breaking off the copper layer. Such metal-coated plastics will be very useful for the fabrication of organic electronic devices.

The ease with which the surface of hard polymers can be activated by zirconium tetra(tert-butoxide) makes it possible to adapt poly(aryl-ether-ether-ketone) (PEEK) as a support for the growth of new bone tissue. Despite ether and ketone being weak ligands, the zirconium intermediary layer on the PEEK surface is still stable to hydrolysis and capable of more than doubling the interfacial shear strength of PEEK.(76) As expected, attachment of RGD onto the zirconium intermediary layer enhanced the osteoconductivity of the PEEK surface. In order to facilitate bone tissue growth, it is desirable that the osteoblasts are guided to grow unilaterally to reproduce the anisotropic nature of bone. With the utility of photolithographic methods, striped patterns of self-assembled monolayer of phosphonates can be laid on polymers to direct growth of cells only along the long axis of the stripes.(77) The patterned surface permits the ECM secreted by the cells to be aligned along the long axis, permitting even decellularized surfaces to continue to be capable of aligning cell growth.(78) A very important feature of this technique is that it is readily scalable, meaning that the technique can indeed be used to coat large (polymeric) replacement bones.

\section{Conclusion}

The utility of stem cells in bone tissue engineering has made great strides, although there are certainly still hurdles to be overcome. As BMSCs are essentially a heterogeneous mixture of cell lineages, more efficient methods for the isolation, purification, and ex vivo expansion of clinical grade BMSCs are needed so that the potency and efficacy of these cells can be improved. As we have also seen, both the physical nanotopography and chemical functionalization of material surface play important roles in determining the success of BMSC osteoinduction and osteoblast attachment, especially for metals and polymers. Thus, it has become possible to make superior composites out of ceramics, metals, and polymers, utilizing the qualities of each type of materials without having to be overly concerned with the osseointegration potential of the resultant composite. Thus, the next challenge is to produce chemically enhanced nanotopographically well-defined surfaces on the orthopedic implant. The synergistic effect of both physical and chemical features can be expected to accelerate the osseointegration of the implant.

\section{Acknowledgments}

S.Z. thanks the National Key Basic Research Program of China (2015CB352006), the National Natural Science Foundation of China (61275006 and 61335011), the Fujian Provincial Youth Top-notch Talent Support Program, the Natural Science Foundation for Distinguished Young Scholars of Fujian Province (2014J06016), the Program from Education Bureau of Fujian Province (JA13060), and the Program for Changjiang Scholars and Innovative Research Team in University (Grant No. IRT1115).

\section{Author Contributions}

All authors participated in developing the ideas presented in this manuscript. Kiat Hwa Chan and Ming Ni conducted the literature research. Kiat Hwa Chan wrote the manuscript. Shuangmu Zhuo and Ming Ni provided valuable suggestions in content and structure of the manuscript. Shuangmu Zhuo performed final editing of the manuscript. All authors read and professionally approved the manuscript.

\section{Conflict of Interest}

The authors declare no conflict of interests in this article.

\section{References}

1. Menendez P, Bueno C, Wang L, Bhatia M. Human embryonic stem cells Potential tool for achieving immuno tolerance? Stem Cell Rev. 2005; 1: 151-8.

2. Blum B, Benvenisty N. The tumorigenicity of human embryonic stem cells. Adv Cancer Res. 2008; 100: 133-58.

3. Bianco P, Riminucci M, Gronthos S, Robey PG. Bone marrow stromal stem cells: nature, biology, and potential applications. Stem Cells 2001; 19: 180-92. 
4. Friedens.AJ, Piatetzk, II, Petrakov.KV. Osteogenesis in transplants of bone marrow cells. J Embryol Exp Morphol. 1966; 16: 381-90.

5. Martin-Rendon E, Brunskill SJ, Hyde CJ, Stanworth SJ, Mathur A, Watt SM. Autologous bone marrow stem cells to treat acute myocardial infarction: a systematic review. Eur Heart J. 2008; 29: 1807-18.

6. Ringden $\mathrm{O}$, Keating A. Mesenchymal stromal cells as treatment for chronic GVHD. Bone Marrow Transplant. 2011; 46: 163-4.

7. Pileggi A. Mesenchymal stem cells for the treatment of diabetes. Diabetes. 2012; 61: 1355-6.

8. Nakamizo A, Marini F, Amano T, Khan A, Studeny M, Gumin J, et al. Human bone marrow-derived mesenchymal stem cells in the treatment of gliomas. Cancer Res. 2005; 65: 3307-18

9. Vainshtein JM, Kabarriti R, Mehta KJ, Roy-Chowdhury J, Guha C. Bone marrow-derived stromal cell therapy in cirrhosis: clinical evidence, cellular mechanisms, and implications for the treatment of hepatocellular carcinoma. Int J Radiat Oncol Biol Phys. 2014; 89: 786-803.

10. Kristjánsson $B$, Honsawek S. Current trends of stem cell-based approaches for osteoarthritis. OA Tiss Eng. 2013;1(1):7.

11. Wei X, Yang X, Han Z-p, Qu F-f, Shao L, Shi Y-f. Mesenchymal stem cells: a new trend for cell therapy. Acta Pharmacol Sin. 2013; 34: 747-54.

12. Dominici M, Le Blanc K, Mueller I, Slaper-Cortenbach I, Marini FC, Krause DS, et al. Minimal criteria for defining multipotent mesenchymal stromal cells. The international society for cellular therapy position statement. Cytotherapy. 2006; 8(4): 315-7.

13. Simmons PJ, Torokstorb B. Identification of stromal cell precursors in human bone-marrow by a novel monoclonal-antibody, Stro-1. Blood. 1991; 78(1): $55-62$.

14. Ringden O, Uzunel M, Rasmusson I, Remberger M, Sundberg B, Lonnies H, et al. Mesenchymal stem cells for treatment of therapy-resistant graft-versus-host disease. Transplantation. 2006; 81(10): 1390-7.

15. Zuk PA, Zhu M, Mizuno H, Huang J, Futrell JW, Katz AJ, et al. Multilineage cells from human adipose tissue: Implications for cell-based therapies. Tissue Engineering. 2001; 7(2): 211-28.

16. Robey PG, Kuznetsov SA, Ren J, Klein HG, Sabatino M, Stroncek DF. Generation of clinical grade human bone marrow stromal cells for use in bone regeneration. Bone. 2015; 70: 87-92.

17. dos Santos F, Andrade PZ, Abecasis MM, Gimble JM, Chase LG, Campbell AM, et al. Toward a clinical-grade expansion of mesenchymal stem cells from human sources: a microcarrier-based culture system under xeno-free conditions. Tissue Eng Part C-Methods. 2011; 17(12): 1201-10.

18. Qiu Q, Ducheyne P, Gao H, Ayyaswamy P. Formation and differentiation of three-dimensional rat marrow stromal cell culture on microcarriers in a rotating-wall vessel. Tissue Eng. 1998; 4(1): 19-34

19. Morgan SM, Tilley S, Perera S, Ellis MJ, Kanczler J, Chaudhuri JB, et al. Expansion of human bone marrow stromal cells on poly-(DL-lactide-co-glycolide) (P(DL)LGA) hollow fibres designed for use in skeletal tissue engineering. Biomaterials. 2007; 28(35): 5332-43.

20. Highfill JG, Haley SD, Kompala DS. Large-scale production of murine bone marrow cells in an airlift packed bed bioreactor. Biotechnol Bioeng. 1996; 50(5): 514-20.

21. Undale AH, Westendorf JJ, Yaszemski MJ, Khosla S. Mesenchymal stem cells for bone repair and metabolic bone diseases. Mayo Clin Proc. 2009; 84(10): 893-902

22. Stroncek DF, Sabatino M, Ren J, England L, Kuznetsov SA, Klein HG, et al. Establishing a bone marrow stromal cell transplant program at the national institutes of health clinical center. Tissue Eng Part B-Rev. 2014; 20(3): 200-5.

23. Dawson JI, Kanczler J, Tare R, Kassem M, Oreffo ROC. Concise review: bridging the gap: bone regeneration using skeletal stem cell-based strategies-where are we now? Stem Cells. 2014; 32(1): 35-44.

24. Jaiswal N, Haynesworth SE, Caplan AI, Bruder SP. Osteogenic differentiation of purified, culture-expanded human mesenchymal stem cells in vitro. Journal of Cellular Biochem. 1997; 64(2): 295-312.

25. zur Nieden NI, Kempka G, Rancourt DE, Ahr HJ. Induction of chondro-, osteo- and adipogenesis in embryonic stem cells by bone morphogenetic protein-2: effect of cofactors on differentiating lineages. BMC Dev Biol. 2005; 5: 1.

26. George J, Kuboki Y, Miyata T. Differentiation of mesenchymal stem cells into osteoblasts on honeycomb collagen scaffolds. Biotechnol Bioeng. 2006; 95(3): 404-11.

27. Sasaki J-I, Hashimoto M, Yamaguchi S, Itoh Y, Yoshimoto I, Matsumoto T, et al. Fabrication of biomimetic bone tissue using mesenchymal stem cell-derived three-dimensional constructs incorporating endothelial cells. PLoS ONE. 2015; 10(6): e0129266.

28. Stevens MM. Biomaterials for bone tissue engineering. Mater Today. 2008;11: 18-25.

29. Chan $\mathrm{KH}$, Zhuo S, Ni M. Natural and synthetic peptide-based biomaterials for bone tissue engineering. OA Tiss Eng. 2013; 1(1): 6 .

30. Yamashita A, Nishikawa S, Rancourt DE. Microenvironment modulates osteogenic cell lineage commitment in differentiated embryonic stem cells. PLoS ONE. 2010; 5(3): e9663.

31. Discher DE, Janmey P, Wang YL. Tissue cells feel and respond to the stiffness of their substrate. Science. 2005; 310(5751): 1139-43.

32. Albrektsson T, Johansson C. Osteoinduction, osteoconduction and osseointegration. Eur Spine J. 2001; 10: S96-S101.
33. Chen W, Shao Y, Li X, Zhao G, Fu J. Nanotopographical surfaces for stem cell fate control: Engineering mechanobiology from the bottom. Nano Today. 2014; 9(6): 759-84.

34. Murphy WL, McDevitt TC, Engler AJ. Materials as stem cell regulators. Nat Mater. 2014;13(6):547-57

35. Zhao C, Xia L, Zhai D, Zhang N, Liu J, Fang B, et al. Designing ordered micropatterned hydroxyapatite bioceramics to promote the growth and osteogenic differentiation of bone marrow stromal cells. J. Mater Chem B. 2015; 3(6): 968-76.

36. Kato RB, Roy B, De Oliveira FS, Ferraz EP, De Oliveira PT, Kemper AG, et al. Nanotopography directs mesenchymal stem cells to osteoblast lineage through regulation of microRNA-SMAD-BMP-2 circuit. J Cell Physiol. 2014; 229(11): 1690-6.

37. Janson IA, Kong YP, Putnam AJ. Nanotopographic substrates of poly (methyl methacrylate) do not strongly influence the osteogenic phenotype of mesenchymal stem cells in vitro. PLoS ONE. 2014; 9(3): e90719.

38. Kim Y, Renner JN, Liu JC. Incorporating the BMP-2 peptide in genetically-engineered biomaterials accelerates osteogenic differentiation. Biomater Sci. 2014; 2(8): 1110-9.

39. Pavlova TV, Pavlova LA, Nesterov AV, Kolesnikov DA, Shchyogolev AI. Comparative characterization of the skull bones after implantation of titanium biocomposites containing BMP-2 in their coating structure. Bull Exp Biol Med. 2014; 158(2): 274-7.

40. Kim M-J, Lee B, Yang K, Park J, Jeon S, Um SH, et al. BMP-2 peptide-functionalized nanopatterned substrates for enhanced osteogenic differentiation of human mesenchymal stem cells. Biomaterials. 2013; 34(30): 7236-46.

41. Benoit DSW, Schwartz MP, Durney AR, Anseth KS. Small functional groups for controlled differentiation of hydrogel-encapsulated human mesenchymal stem cells. Nat Mater. 2008; 7(10): 816-23.

42. Nuttelman CR, Benoit DSW, Tripodi MC, Anseth KS. The effect of ethylene glycol methacrylate phosphate in PEG hydrogels on mineralization and viability of encapsulated hMSCs. Biomaterials. 2006; 27(8): 1377-86.

43. Curran JM, Chen R, Hunt JA. The guidance of human mesenchymal stem cell differentiation in vitro by controlled modifications to the cell substrate. Biomaterials. 2006; 27(27): 4783-93.

44. Currey JD. Bones: Structure and mechanics. Princeton, New Jersey, USA: Princeton University Press; 2006: 456p.

45. Damien CJ, Parsons JR. Bone-graft and bone-graft substitutes - a review of current technology and applications. J Appl Biomater. 1991; 2(3): 187-208.

46. Ducheyne P, Qiu Q. Bioactive ceramics: the effect of surface reactivity on bone formation and bone cell function. Biomaterials. 1999; 20(23-24): 2287-303.

47. Hyakuna K, Yamamuro T, Kotoura Y, Kakutani Y, Kitsugi T, Takagi H, et al. The influence of calcium-phosphate ceramics and glass-ceramics on cultured-cells and their surrounding media. J Biomed Mater Res. 1989; 23(9): $1049-66$

48. ElGhannam A, Ducheyne P, Shapiro IM. Formation of surface reaction products on bioactive glass and their effects on the expression of the osteoblastic phenotype and the deposition of mineralized extracellular matrix. Biomaterials. 1997; 18(4): 295-303.

49. Grayson WL, Bunnell BA, Martin E, Frazier T, Hung BP, Gimble JM. Stromal cells and stem cells in clinical bone regeneration. Nat Rev Endocrinol. 2015; 11(3): 140-50.

50. Lee W-H, Loo C-Y, Rohanizadeh R. A review of chemical surface modification of bioceramics: effects on protein adsorption and cellular response. Colloids Surf B Biointerfaces. 2014; 122: 823-34

51. Lee W-H, Loo C-Y, Van KL, Zavgorodniy AV, Rohanizadeh R. Modulating protein adsorption onto hydroxyapatite particles using different amino acid treatments. J R Soc Interface. 2012; 9(70): 918-27.

52. Lee W-H, Loo C-Y, Zavgorodniy AV, Rohanizadeh R. High protein adsorptive capacity of amino acid-functionalized hydroxyapatite. J Biomed Mater Res Part A. 2013; 101(3): 873-83.

53. Durrieu MC, Pallu S, Guillemot F, Bareille R, Amedee J, Baquey C, et al. Grafting RGD containing peptides onto hydroxyapatite to promote osteoblastic cells adhesion. J Mater Sci Mater Med. 2004; 15(7): 779-86.

54. Zurlinden K, Laub M, Jennissen HP. Chemical functionalization of a hydroxyapatite based bone replacement material for the immobilization of proteins. Material Wiss Werkst 2005;36(12):820-7.

55. Balasundaram $\mathrm{G}$, Sato M, Webster TJ. Using hydroxyapatite nanoparticles and decreased crystallinity to promote osteoblast adhesion similar to functionalizing with RGD. Biomaterials. 2006; 27(14): 2798-805.

56. Yang $C$, Cheng $K$, Weng W, Yang C. Immobilization of RGD peptide on HA coating through a chemical bonding approach. J Mater Sci Mater Med. 2009; 20(11): 2349-52.

57. Schickle K, Zurlinden K, Bergmann C, Lindner M, Kirsten A, Laub M, et al. Synthesis of novel tricalcium phosphate-bioactive glass composite and functionalization with rhBMP-2. J Mater Sci Mater Med.2011; 22(4): 763-71.

58. Zhou Y-L, Niinomi M, Akahori T, Nakai M, Fukui H. Comparison of various properties between titanium-tantalum alloy and pure titanium for biomedical applications. Mater T JIM. 2007; 48(3): 380-4.

59. Solar RJ. Corrosion resistance of titanium surgical implant alloys: A review. In: Syrett BC, Acharya A, editors. Corrosion and degradation of implant materials. ASTM STP 684: American Society for Testing and Materials. 1979:259-73. 
60. Ungersboeck A, Geret V, Pohler O, Schuetz M, Wuest W. Tissue reaction to bone plates made of pure titanium - a prospective, quantitative clinical-study. J Mater Sci Mater Med. 1995; 6(4): 223-9.

61. Lalor PA, Revell PA, Gray AB, Wright S, Railton GT, Freeman MAR. Sensitivity to titanium - a cause of implant failure. J Bone Joint Surg Br. 1991; 73(1): 25-8.

62. Witt JD, Swann M. Metal wear and tissue-response in failed titanium-alloy total hip replacements. J Bone Joint Surg Br. 1991; 73(4): 559-63.

63. Gawalt ES, Avaltroni MJ, Koch N, Schwartz J. Self-assembly and bonding of alkanephosphonic acids on the native oxide surface of titanium. Langmuir. 2001; 17(19): 5736-8.

64. Gawalt ES, Brault-Rios K, Dixon MS, Tang DC, Schwartz J. Enhanced bonding of organometallics to titanium via a titanium(III) phosphate interface. Langmuir. 2001; 17(21): 6743-5.

65. Hanson EL, Schwartz J, Nickel B, Koch N, Danisman MF. Bonding self-assembled, compact organophosphonate monolayers to the native oxide surface of silicon. J Am Chem= Soc. 2003; 125(51): 16074-80.

66. Gawalt ES, Avaltroni MJ, Danahy MP, Silverman BM, Hanson EL, Midwood KS, et al. Bonding organics to Ti alloys: Facilitating human osteoblast attachment and spreading on surgical implant materials. Langmuir. 2003; 19(1): 200-4.

67. Gawalt ES, Avaltroni MJ, Danahy MP, Silverman BM, Hanson EL, Midwood $\mathrm{KS}$, et al. Bonding organics to Ti alloys: Facilitating human osteoblast attachment and spreading on surgical implant materials corrections (vol 19, pg 200, 2003). Langmuir. 2003; 19(17): 7147-7147.

68. Schwartz J, Avaltroni MJ, Danahy MP, Silverman BM, Hanson EL, Schwarzbauer JE, et al. Cell attachment and spreading on metal implant materials. Mater Sci Eng C-Biomimetic and Supramolecular Systems. 2003; 23(3): 395-400.

69. Danahy MP, Avaltroni MJ, Midwood KS, Schwarzbauer JE, Schwartz J. Self-assembled monolayers of alpha,omega-diphosphonic acids on Ti enable complete or spatially controlled surface derivatization. Langmuir. 2004; 20(13): 5333-7.

70. Shannon FJ, Cottrell JN, Deng X-H, Crowder KN, Doty SB, Avaltroni MJ, et al. A novel surface treatment for porous metallic implants that improves the rate of bony ongrowth. J Biomed Mater Res Part A. 2008; 86A(4): 857-64.

71. Khan F, Smith JO, Kanczler JM, Tare RS, Oreffo ROC, Bradley M. Discovery and Evaluation of a Functional Ternary Polymer Blend for Bone Repair: Translation from a Microarray to a Clinical Model. Adv Funct Mater. 2013; 23(22): 2850-62.

72. Kurtz SM, Devine JN. PEEK biomaterials in trauma, orthopedic, and spinal implants. Biomaterials. 2007; 28(32): 4845-69.

73. Dennes TJ, Hunt GC, Schwarzbauer JE, Schwartz J. High-yield activation of scaffold polymer surfaces to attach cell adhesion molecules. J Am Chem Soc. 2007; 129(1): 93-7.

74. Dennes TJ, Schwartz J. Controlling cell adhesion on polyurethanes. Soft Matter. 2008; 4(1): 86-9.

75. Dennes TJ, Schwartz J. A nanoscale metal alkoxide/oxide adhesion layer enables spatially controlled metallization of polymer surfaces. ACS Appl Mater Interfaces. 2009; 1(10): 2119-22.

76. Dennes TJ, Schwartz J. A nanoscale adhesion layer to promote cell attachment on PEEK. J Am Chem Soc. 2009; 131(10): 3456-7.

77. Donnelly PE, Jones CM, Bandini SB, Singh S, Schwartz J, Schwarzbauer JE. A simple nanoscale interface directs alignment of a confluent cell layer on oxide and polymer surfaces. J Mater Chem B. 2013; 1(29): 3553-61.

78. Singh S, Bandini SB, Donnelly PE, Schwartz J, Schwarzbauer JE. A cell-assembled, spatially aligned extracellular matrix to promote directed tissue development. J Mater Chem B. 2014; 2(11): 1449-53. 